\title{
Co-gasification of pyrolysis oil and black liquor for methanol production
}

\author{
Jim Andersson ${ }^{1, *}$, Joakim Lundgren ${ }^{1}$ and Erik Furusjö ${ }^{1,2}$ \\ ${ }^{1}$ Luleå University of Technology, Department of Engineering Sciences and Mathematics, Division of Energy Science, \\ Universitetsområdet Porsön, SE-971 87, Luleå, Sweden \\ ${ }^{2}$ Chemrec AB, Drottning Kristinas väg 61, SE-114 28 Stockholm, Sweden \\ *Corresponding email: jim.andersson@ltu.se
}

\begin{abstract}
It has previously been shown that an investment in a black liquor gasification (BLG) plant is advantageous regarding efficiency and economic performance compared to a new recovery boiler investment for pulp mills. However, the availability of black liquor is limited and strongly connected to the pulp production. This limits the maximum production capacity and requires high availability of the BLG plant to ensure that the crucial cooking chemicals in the black liquor can be returned to the pulp mill. One alternative to increase the motor fuel production volumes and improve the operational flexibility of the BLG plant is to add pyrolysis oil to the black liquor feed and co-gasify the blend. Furthermore, the catalytic alkali metals in the black liquor enhance the conversion rates in a reactor, leading to a higher syngas quality achieved at lower temperatures when gasifying a blend compared to unblended pyrolysis oil. The objective of this study was to techno-economically investigate the opportunity to increase methanol production at a pulp mill via co-gasification of pyrolysis oil and black liquor. Gasifying a blend consisting of $25 \%$ pyrolysis oil and $75 \%$ black liquor on wet mass basis nearly doubles the methanol production, compared to gasifying the available black liquor only. For a 50/50 blend the methanol production increases by more than 250\%. According to published data, pyrolysis oil can be bought to a cost around $70 € / M W h$. This corresponds to an increase in IRR for the investment in the 25/75 and the 50/50 blend case with 4\%-units and 6\%-units, respectively, compared to the IRR (17.5\%) for the BLG plant. Cogasification of black liquor and pyrolysis oil is an attractive investment opportunity that will increase the methanol production volume and add extra revenues per produced unit compared to methanol produced via gasification of pure black liquor.
\end{abstract}

\section{KEYWORDS: Black liquor, Pyrolysis oil, Co-gasification, Methanol, Pulp mill}

\section{INTRODUCTION}

Production of renewable motor fuels and chemicals is important in the development towards a more sustainable society where fossil fuels are replaced. To be able to compete with fossil resources, efficient production of biomass based products is necessary to maximize overall process economics and to minimize negative environmental impact. In order to obtain reasonable production costs, large biorefinery plants will likely be required to reach favorable economy-of-scale effects [1]. Integrating large scale biofuel production processes in existing forest industries provides large feedstock handling and logistical advantages [2]. Gasification of black liquor can for example be applied in chemical pulp mills and has been successfully demonstrated in a 3 MW pilot scale in Piteå in Sweden [3, 4]. Compared to combustion of black liquor in a recovery boiler, black liquor gasification and subsequent synthesis for motor fuel production show advantages regarding economic performance and energy efficiency. The available volume of black liquor is however limited and strongly connected to the pulp production, which thereby also limits the potential motor fuel production. Furthermore a high availability of the gasification plant is required to ensure that crucial cooking chemicals in the black liquor are returned to the pulp mill. One way to increase the production of motor fuel as well as the operation flexibility of the black liquor gasifier is to add biomass based pyrolysis oil to the black liquor stream and co-gasify the blend. The energy content in biomass based pyrolysis oil is almost twice as high as the black liquor energy content. A fifty-fifty blend of a typical pyrolysis oil and black liquor has many similarities to sulfite thick liquor, e.g. heating value and alkali metal content. Also, many of the organic constituents of pyrolysis oil are expected to be similar to the organic components of black liquor from the pulp industry because of similar origin. A fifty-fifty blend would roughly triple the energy input to the gasification plant. This would result in increased production volumes and the economy-of -scale effects in the downstream gas conditioning and synthesis which may lower the production cost.

Pyrolysis oil can be produced from various types of biomass such as straw, wood and wood waste, through a variety of technologies. Pyrolysis oil can be used in a number of applications, including co-firing with fossil fuels in power plants. There is much interest in the technology for production of green chemicals and fuels. One possible route is to gasify pyrolysis oil to a syngas that can be used as raw material for various petrochemical processes. Research has shown that a high gasification temperature or a catalytic bed is required to produce a syngas with high quality [5,6]. Without a catalytic material, gasification of pyrolysis oil requires substantially higher temperatures compared to gasification of black liquor to obtain a similar gas quality and carbon conversion. This is at least partly due to the lack of catalytic alkali metals in pyrolysis oil. Sulfite thick liquor, which is similar to black liquor but comes from an alternative pulping process, has a 50\% higher energy content and a 50\% lower alkali content compared to black liquor. During an experiment in the $3 \mathrm{MW}$ black liquor gasification pilot, the sulfite thick liquor was gasified 
with excellent performance under virtually the same processing conditions normally used for the black liquor, which indicates that $50 \%$ less alkali still provides sufficient catalytic activity.

The main aim of this study was to techno-economically investigate the opportunity to increase methanol production at a Swedish pulp mill (the Rottneros Vallvik plant) via co-gasification of pyrolysis oil and black liquor. The objective was to evaluate the feasibility of the incremental methanol production capacity compared to a black liquor gasification plant for methanol production as reference. This was done by calculating the overall energy efficiency for two blend ratios, i.e. $25 \%$ and $50 \%$ pyrolysis oil of the total wet feed. The evaluation of the process economics was done by a cash flow analysis to determine the internal rate of return (IRR) for three different cases.

\section{MATERIAL AND METHODS}

\subsection{GASIFICATION MODELING}

A pressurized oxygen-blown entrained flow gasifier based on the Chemrec black liquor gasification (BLG) technology was considered. Simulations were made for a $0-50 \%$ pyrolysis oil blend using a thermodynamic model developed for gasification of black liquor. The model uses thermodynamic data from Lindberg, [7] for pure inorganic components and from Knacke, et al. [8] for remaining species. Empirical modifications, based on operating experience from the BLG pilot plant in Piteå Sweden [4, 9 , 10], are used for $\mathrm{CH}_{4}$ and $\mathrm{H}_{2} \mathrm{~S} / \mathrm{COS}$ concentrations in the gas, since these are not well described by thermodynamic equilibrium [11]. Simulations represent a realistic gasifier size and heat losses for a commercial implementation of black liquor/pyrolysis oil co-gasification. Table 1 shows heating values and chemical compositions of black liquor and pyrolysis oil used in the modeling. The same mass flow of black liquor, corresponding to the full pulp mill production, was used in all cases. Results should not be generalized without considering that pyrolysis oil composition can vary widely depending on raw material and pyrolysis process.

Table 1. Black liquor and pyrolysis oil specification used for simulations

\begin{tabular}{lcc}
\hline & Black liquor $^{\mathrm{A}}$ & Pyrolysis oil $^{\mathrm{B}}$ \\
\hline $\mathrm{DS}$ [w\%] & $73.2 \%$ & $75.0 \%$ \\
LHV MJ/kg solids & 12.13 & 21.3 \\
& & \\
$\mathrm{~S}$ [kg/kg solids] & $5.52 \%$ & \\
$\mathrm{Cl}[\mathrm{kg} / \mathrm{kg}$ solids] & $0.13 \%$ & \\
$\mathrm{C}[\mathrm{kg} / \mathrm{kg}$ solids] & $32.50 \%$ & $61.33 \%$ \\
$\mathrm{H}$ [kg/kg solids] & $3.40 \%$ & $4.30 \%$ \\
$\mathrm{~N}[\mathrm{~kg} / \mathrm{kg}$ solids] & $0.08 \%$ & $0.01 \%$ \\
$\mathrm{Na}[\mathrm{kg} / \mathrm{kg}$ solids] & $20.23 \%$ & \\
$\mathrm{~K}$ [kg/kg solids] & $2.18 \%$ & \\
$\mathrm{O}[\mathrm{kg} / \mathrm{kg}$ solids] & $35.96 \%$ & $34.40 \%$ \\
\hline
\end{tabular}

${ }^{\mathrm{A}}$ Model composition for pulp mill using the Kraft pulping process.

${ }^{\text {B }}$ From the BTG web site, http://www.btgworld.com/nl/rtd/technologies/fast-pyrolysis , accessed April 1, 2013

Alkali metals are known to catalyze gasification reactions [12-14] and this is believed to be an important explanation for the very high carbon conversion obtained for gasification of black liquor at relatively low global temperature of approximately $1000 \mathrm{C}$. Simulations have been executed assuming that the co-gasification process can use the same process temperature as for black liquor gasification. This relies on the assumption that a similar catalytic effect from black liquor sodium content can be realized in the cogasification process, although the alkali content of the mixed feedstock is lower. This assumption is supported by recent experimental work with up to $30 \%$ pyrolysis oil ${ }^{1}$, pilot experiments using a pulping liquor with lower sodium content [15] and earlier work indicating that a lower sodium content than what is present in black liquor can still achieve the required catalytic effects [16].

The simulations show that the cold gas efficiency (CGE) increases with the proportion of pyrolysis oil as shown in Figure 1. Cold gas efficiency increases from almost $70 \%$ to $80 \%$ when going from pure back liquor to a mixture with $50 \%$ pyrolysis oil. The incremental efficiency of added pyrolysis oil, using black liquor gasification a reference, is $80-85 \%$. This high number is due to the lower temperature enabled by the catalytic effect from the black liquor sodium and would be difficult to achieve for unblended pyrolysis oil.

The reason for increased efficiency compared to unblended black liquor gasification is primarily that the inorganic content of the gasification feedstock decreases significantly, which decreases the thermal ballast of the system. Sulfur-free heating values are used, since sulfur exits the gasifier in reduced form and must be returned to the host pulp mill as such to enable recovery of

${ }^{1}$ B. Albert, et al. Efficient gasification of biomass via pyrolysis/liquefaction and catalyst addition: char gasification reactivity. Manuscript in preparation (2013). 
cooking chemicals. It should be noted that increased cold gas efficiency is associated with a decreased low pressure steam production from the gas cooling unit from approximately 0.28 to 0.20 ton steam/ $\mathrm{MW}_{\text {th }}$ feed.

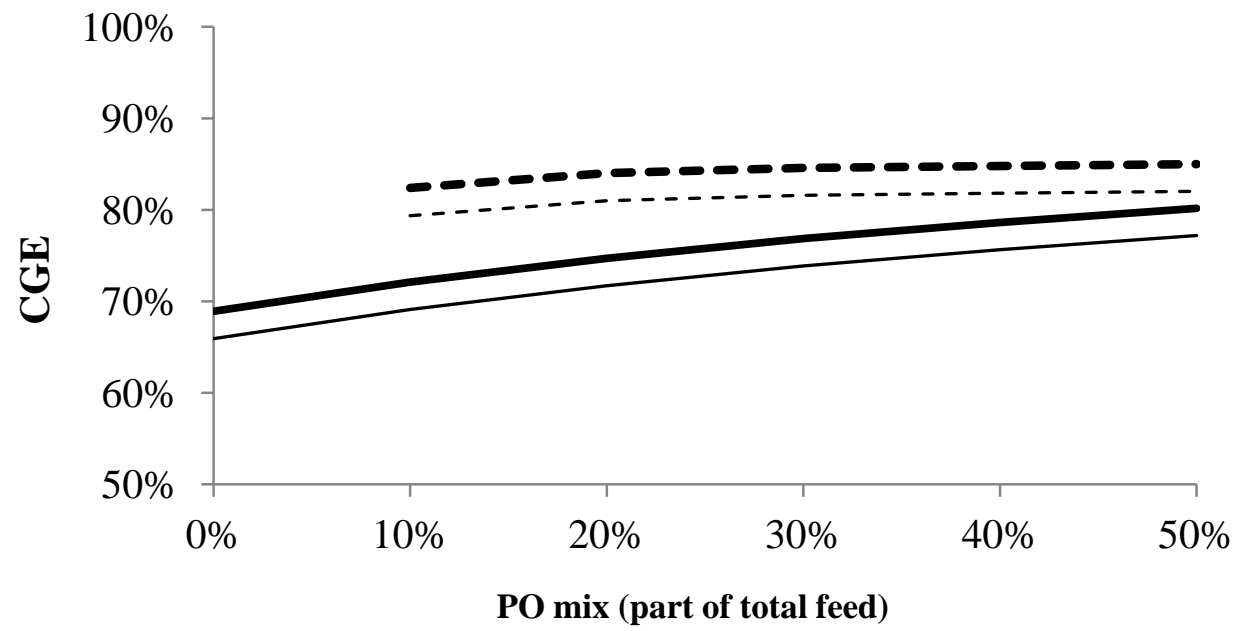

Figure 1. Simulated cold gas efficiency of gasification process for varying pyrolysis oil fraction Calculations use using sulfur-free heating values (thick lines) or only $\mathrm{H} 2$ and $\mathrm{CO}$ components of synthesis gas (thin lines). Dashed lines represent the incremental efficiency for pyrolysis oil using gasification of only black liquor as reference.

Changing synthesis gas composition and decreased specific oxygen consumption are associated with the higher efficiency

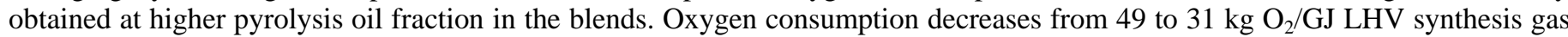
when changing from pure black liquor feedstock to a 50/50 blend. Carbon dioxide content in the synthesis gas from the gasification unit decreases from 28 mole $\%$ to 18 mole\% while the CO concentration increases from $30 \mathrm{~mol} \%$ to $42 \mathrm{~mol} \%$. Hydrogen concentration changes only marginally. The methanol production and operation of the gasification units (CHU:s) for the different blends was modeled using the syngas composition from the SIMGAS simulations. This includes the specific oxygen consumption for the gasifiers and specific steam generation from gas cooling unit. The consequences for downstream gas cleaning and conditioning processes are discussed below.

\subsection{SYSTEM EVALUATION AND ECONOMICS}

A schematic view of the biofuel plant (BFP), i.e. a BLG plant including methanol synthesis, is illustrated in Figure 2. This configuration assumes external oxygen supply. The same setup of units would be valid for the co-gasification alternatives, with the addition of a pyrolysis oil supply, also some operational changes and adjustments for the gasifier units (CHU:s).

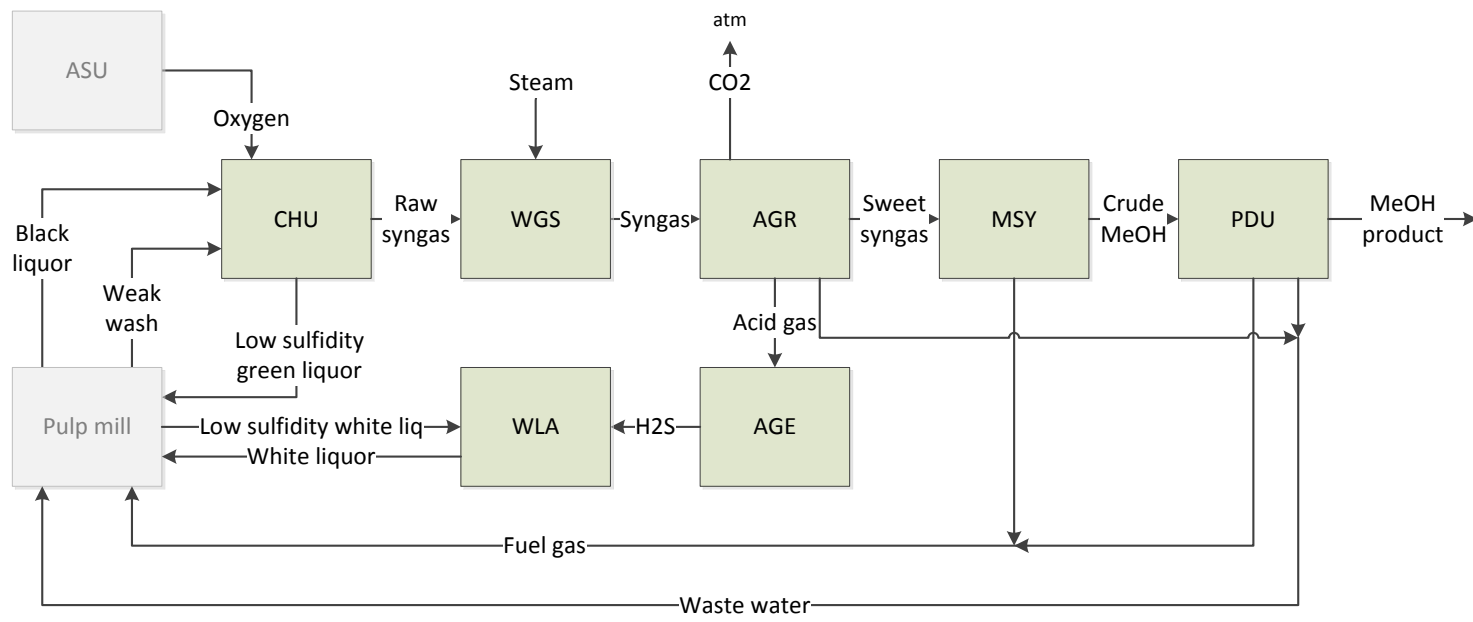

Figure 2. Simplified flowsheet for the methanol production plant.

The BFP was modeled using Mixed Integer Linear Programming (MILP) through the Java-based software tool reMIND [17]. The model structure is represented by a network of nodes and branches, each node contains linear equations to express the materials and energy balances of each steam and power consuming/generating unit in the BFP. The pulp mill's power and steam balance was represented by a black box approach valid for the increased pulp production capacity (see Table 2). The branches connect the units by representing the internal network of material and energy flows. Power and steam flows of each BFP units were scaled according performance of a reference BLG plant that produces $100 \mathrm{MW}$ methanol [18]. 
Utility requirements for the water gas shift (WGS) reactor and the acid gas removal (AGR) units were scaled according to the syngas flow and the flow of gas species required to be removed, respectively. The methanol flow was used for the other units. The modeling objective was to guarantee that the pulp production is unaffected when a BFP is integrated. The primary modeling constraint was therefore to ensure that sufficient amount of steam is available for the pulp making, done by adjusting biomass supply to the bark boiler. Integration of a BLG plant is also associated with an increased lime kiln fuel demand due to somewhat different green liquor composition, which is accounted for in the analysis. According to [19], the changed composition of the green liquor can be compensated by increasing the causticization by $25 \%$, i.e. increasing the lime kiln fuel demand. The purge gas from synthesis loop in the BFP is a valuable gas that can be used as supplement to the lime kiln fuel. The lime kiln fuel import demand can therefore potentially be lower after the integration depending on the amount of available purge gas from the BFP.

The Rottneros Vallvik mill produces two pulp products, ECF (Elemental Chlorine Free bleached pulp) and UKP (Unbleached Kraft pulp). During the UKP production the flow rate and energy content of the black liquor is lower than for the ECF. On a yearly basis the black liquor energy content is reduced with roughly 3\% compared to a maximum continuous ECF production. The operation of the mill is affected by the UKP production; these changes have however not been explicitly addressed in the evaluation. The plant operation is based to match the yearly operation average of the Rottneros Vallvik mill during 348 days with a $90 \%$ availability compensated for lower black liquor energy content during the UKP production. This corresponds to a black liquor availability of $180 \mathrm{MW}$ (SF-LHV) or $1500 \mathrm{tDS} / \mathrm{h}$ during 7517 hours. Sulfur free lower heating value (SF-LHV) is used as basis for calculations since the sulfur in the black liquor is returned in reduced form to the mill (as sodium sulfide in green liquor). Hence, the heating value of sulfur species is not useful. The same overall capacity utilization for the BFP plant (90\% of scheduled operation time) has been used for all cases.

Table 2. Important key energy data for the pulp mill representing a yearly average production with a recovery boiler.

\begin{tabular}{lcc}
\hline BL & ton DS/d & 1500 \\
- LHV (on dry basis) & MW & 210 \\
- SF-LHV (on dry basis) & MW & 180 \\
Mill Power demand & MW & 28 \\
Steam turbine power production & MW & 22 \\
Lime kiln fuel & MW & 18 \\
Bark available for export $(65 \% \mathrm{DS})^{\mathrm{A}}$ & MW & 29 \\
\hline${ }^{\mathrm{A}}$ The energy content of the falling bark is based on $35 \%$ moisture content. Actually moisture content before drying is $65 \%$.
\end{tabular}

The overall system efficiency was calculated by using the pulp mill including the BFP as system boundaries. The production of bio-oil is assumed to be delivered to the gate (not an integrated production unit(s) within the mill). However, the effect on the system efficiency when the losses in pyrolysing forest residues to bio-oil are included has also been investigated, by accounting a biomass to oil conversion efficiency of 55\%. The overall system efficiencies for all cases were calculated based on the marginal energy supply compared to the pulp mill with an upgraded recovery boiler including the utility requirements for the ASU. Note that oxygen is bought "over the fence" but the utility requirements for the ASU are included in the overall system efficiency calculations to increase the system boundaries and to apply a more global approach. The calculations were done using electrical equivalents. The energy carriers (methanol, biomass, etc) were converted to their electricity equivalents according to the efficiency $(\eta)$ of the best-available technologies known to the authors according to Table 3. Biomass used directly for the pulp making is not included in the calculation of the overall energy system efficiencies.

Table 3. Power generation efficiencies used for calculation of electricity equivalents

\begin{tabular}{lcc}
\hline Energy carrier & Power generation efficiency $(\eta)$ & Reference \\
\hline Biomass & $46.2 \%$ & {$[20]$} \\
Methanol & $55.9 \%$ & {$[20]$} \\
LPG & $57.6 \%$ & Assumed the same as for SNG [20] \\
Pyrolysis oil & $50 \%$ & Assumed \\
\hline
\end{tabular}

The incremental investment cost was calculated for all gasification cases as a comparison between an investment in a rebuild recovery boiler and methanol production via the gasification alternatives. The investment costs for the BFP pathways are scaled using a 0.65 scaling exponent for all units, except for the gasification units. The gasification unit of the BFP plant uses a multitrain arrangement. The maximum capacity for each individual gasifier was based on what is commercially offered by Chemrec for black liquor gasification, which is approximately $70 \mathrm{MW}_{\mathrm{th}}$ feed. The capacity is determined by a combination of gas residence time and inorganic smelt load on critical components [18]. Due to the lower inorganic content of black liquor/pyrolysis oil mixtures it has been assumed that the capacity can increase by $20 \%$ compared to operation on pure black liquor with the same unit cost. This means that the maximum capacity used for each gasifier train is $85 \mathrm{MW}_{\text {th }}$ feed. The investment costs for the other units were determined according the following relation: 


$$
C=C_{r e f} \cdot\left(\frac{S}{S_{\text {ref }}}\right)^{0.65}
$$

Eq 1

$\mathrm{C}$ and S refer to the investment cost and the scaling size of each unit, respectively. The subscript (ref) denotes the investment cost and size of the reference units. Cost information was supply by [18], for a $100 \mathrm{MW}$ methanol BLG plant. Used scale parameter for the different units is listed in Table 4.

\begin{tabular}{lc}
\multicolumn{2}{c}{ Table 4. Scale parameters used for investment cost calculation in Eq 1.} \\
\hline Unit & Scale parameter \\
\hline Gasification units (CHU:s) & Nr of trains \\
Sour shift (WGS) & Dry gas flow \\
Acid gas removal (AGR) & $\mathrm{CO}_{2}$ flow \\
MeOH synthesis (MSY) & $\mathrm{MeOH}$ flow \\
MeOH distillation (PDU) & $\mathrm{MeOH}$ flow \\
Acid gas enrichment (AGE) & Same for all \\
White liquor adsorption (WLA) & Same for all \\
MeOH storage & $\mathrm{MeOH}$ flow \\
Balance of the plants & $\mathrm{MeOH}$ flow \\
Thermal oxidizer & Same for all \\
Flare stack with safety zone & $\mathrm{MeOH}$ flow \\
\hline
\end{tabular}

In Table 5, cost and selling price for the different commodities and products are listed. The methanol selling price is used for determining the internal rate of return (IRR) in a cash flow analysis. The analysis considers a three year construction time. During the first production year it is assumed that only $60 \%$ of the maximum methanol production capacity is achieved. Second year and third year, are assumed to give $80 \%$ and $95 \%$ of the nominal capacity respectively. Full production is not reached until the fourth year.

Table 5. Feedstock costs and product prices [18].

\begin{tabular}{lccc}
\hline Consumables and products & \multicolumn{1}{c}{ Comment } & Cost & Unit \\
\hline Biomass fuel cost & $2.94 \mathrm{MWh} /$ ton (40\% moisture) & 28 & $€ / \mathrm{MWh}$ \\
Power & & 57 & $€ / \mathrm{MWh}$ \\
Pyrolysis oil cost ${ }^{\mathrm{A}}$ & $4.27 \mathrm{MWh} /$ ton $(25 \%$ moisture $)$ & $35-115$ & $€ / \mathrm{MWh}$ \\
Oxygen cost & 69 & $€ /$ ton \\
Lime kiln fuel & 46 & $€ / \mathrm{MWh}$ \\
Methanol & & 984 & $€ /$ ton \\
\hline \multicolumn{2}{c}{ Assumed cost span for pyrolysis oil. }
\end{tabular}

The lowest production cost for pyrolysis oil was found in [21], where bio-oil was reported to be produced to a cost of $35 € / \mathrm{MWh}$ in a large scale production facility $(2000 \mathrm{t} / \mathrm{d})$. A single facility with this capacity is not yet commercially available and the production cost could instead be used as an indication on the potential cost for pyrolysis oil production in the future. Another study, where pyrolysis oil was assumed to replace coal in a power plant in Finland, has estimated the pyrolysis oil cost to be in the range of 45-66 €/MWh [22]. The wide range depends on the locations of the biomass resources and the power plants as well as the (potential) annual pyrolysis oil demand and potential sites for process integration. Bio-oil production costs in the similar range (51-67 €/MWh) was reported for a production facility integrated with a bubbling fluidized bed for bio-oil and district heating production $^{2}$. According to [23], a $30 \mathrm{MW}$ pyrolysis oil plant integrated in CHP plants can produce bio-oil to a cost in the range 50$66 € / \mathrm{MWh}$. The corresponding range for $60 \mathrm{MW}$ oil production integrated in pulp mills is $43-48 € / \mathrm{MWh}$. The production cost is valid for wood-chips with a $62 \%$ biomass-to-oil thermal efficiency, on wet LHV basis. Benjanminsson, et al. [23], also estimated that a 15 MW decentralised stand-alone pyrolysis oil plant can produce bio-oil to a cost of $62 € / \mathrm{MWh}$, at the same thermal efficiency as mentioned above. Pyrolysis of forest residues may reach a lower efficiency, around 50\% This increases the production cost to $77 € / \mathrm{MWh}[23]$.

${ }^{2}$ Y. Solantausta. Fast pyrolysis of forest residue - Cost and performance analysis (Presentation). VTT Technical research centre of Finland, 2013. 


\subsection{DESCRIPTION OF THE CASE STUDY}

Today the Rottneros Vallvik Kraft pulp mill is planning upgrades to increase the pulp production capacity. To raise the pulp production, debottlenecking investments are required in the recovery boiler, the causticizing/lime kiln, pulp dryer and steam turbine. Investments in upgrading the capacity of the evaporation and auxiliary systems have already been conducted. The single largest investment for increasing capacity of the mill, to rebuild the recovery boiler to support the higher pulp capacity (39 M€), would be avoided for all the methanol production cases. This is due to that the gasification units replace the recovery boiler. Another $11 \mathrm{M} €$ in mill upgrading investments are also avoided for the BFP pathways, since they are replaced by other investments included in the BFP scope.

Three methanol capacity levels was considered (i) Case BLG, a reference methanol production level, where only the available black liquor is gasified for methanol production, (ii) Case 25, a medium methanol production capacity, where a blend of $25 \%$ pyrolysis oil and $75 \%$ black liquor of the total wet feedstock mass flow is gasified and (iii) Case 50, where a fifty-fifty blend is gasified for a high methanol production level. Table 6 summarized the yearly average mass and energy flows for pyrolysis oil and black liquor for the three cases.

A BLG plant is normally designed with a redundant gasifier train to ensure the high availability required to support the mill with black liquor processing capacity. For the BLG reference case of this study this leads to a 4x33\% design of the gasification unit. When a second feedstock is introduced by mixing pyrolysis oil with the black liquor from the pulp mill, an improved operational flexibility can be obtained for the BFP plant. The redundant gasifier is no longer essential to ensure black liquor processing capacity, since the full black liquor flow can be processed even when one gasifier train is shut-down for maintenance by decreasing the fraction of pyrolysis oil feed. Based on the mass and energy flows (Table 6) and previously mentioned crucial design parameters (Section 2.2), this corresponds to 4x25\% and 7x14\% designs in Case 25 and Case 50, respectively. The removal of the redundant gasifier will lead to temporarily lower capacity when gasifier maintenance is carried out but this is compensated by the higher capacity utilization obtained by mixing a larger fraction of pyrolysis oil into black liquor when the pulp mill is running at reduced capacity. Note that, for the co-gasification cases (Case 25 and 50) it is possible and would probably be wise to compensate for the lower black liquor energy content during the UKP production by increasing the consumption of pyrolysis oil so that the full capacity of the downstream units can be used, although this has not been considered in this study.

Table 6. Annual average mass and energy flows for the different blends.

\begin{tabular}{lcccc}
\hline Case BLG & Case BLG & Case 25 & Case 50 & Unit \\
\hline Black liquor & 180 & 180 & 180 & MW (SF LHV) \\
Black liquor & 2049 & 2049 & 2049 & ton/d (73.20\% DS) \\
Pyrolysis oil & 0 & 122 & 365 & MW (LHV) \\
Pyrolysis oil & 0 & 683 & 2049 & ton/d (75\% DS) \\
\hline
\end{tabular}

\section{RESULTS AND DISCUSSION}

By blending biomass based pyrolysis oil with a fixed amount of black liquor increases the total energy input considerably, due to the increased total feedstock flow and the higher heating value of the pyrolysis oil. Gasifying a 50/50 blend more than triples the sulfur-free heat input to the gasifier for a given black liquor flow. As a positive consequence, the cold gas efficiency (CGE) is also improved. Case BLG receives a CGE of 70\% (SF-LHV basis), while the CGE is increased with 7\%-units and 11\%-unit for Case 25 and Case 50, respectively. A higher CGE leads to higher concentration of carbon monoxide and lower carbon dioxide content in the syngas, see Figure 3. More medium pressure (MP) steam per ton of syngas is therefore required to shift the syngas to the desired H2:CO-ratio suitable for methanol synthesis for the co-gasification cases. In all cases, the BFP have a MP steam deficit and a surplus of low pressure (LP) steam. The mill is therefore required to supply MP steam to the BFP whilst surplus LP steam can be returned to the pulp making processes. A higher CGE reduces the potential heat recovery per ton of syngas generated. The amount of LP steam delivered to the mill is reduced to half, per ton of methanol, for Case 50 compared to Case BLG.

Utility requirement for an Acid Gas Removal (AGR) unit is primary steam and power. The demand is mainly controlled by the quantities of gas species that are required to be removed (mainly $\mathrm{CO}_{2}$ and to some extend $\mathrm{H}_{2} \mathrm{~S}$ and COS). As seen in Figure 3 , after the shift process the carbon dioxide content of the syngas is declining when pyrolysis oil content in the blend is increasing. Less steam and power is therefore required in the AGR per ton of syngas for higher blend ratios. This partly compensates for the increased MP steam use in the WGS. The fifty-fifty blend requires 20\% higher MP steam import from the mill per ton of methanol compared to Case BLG. 


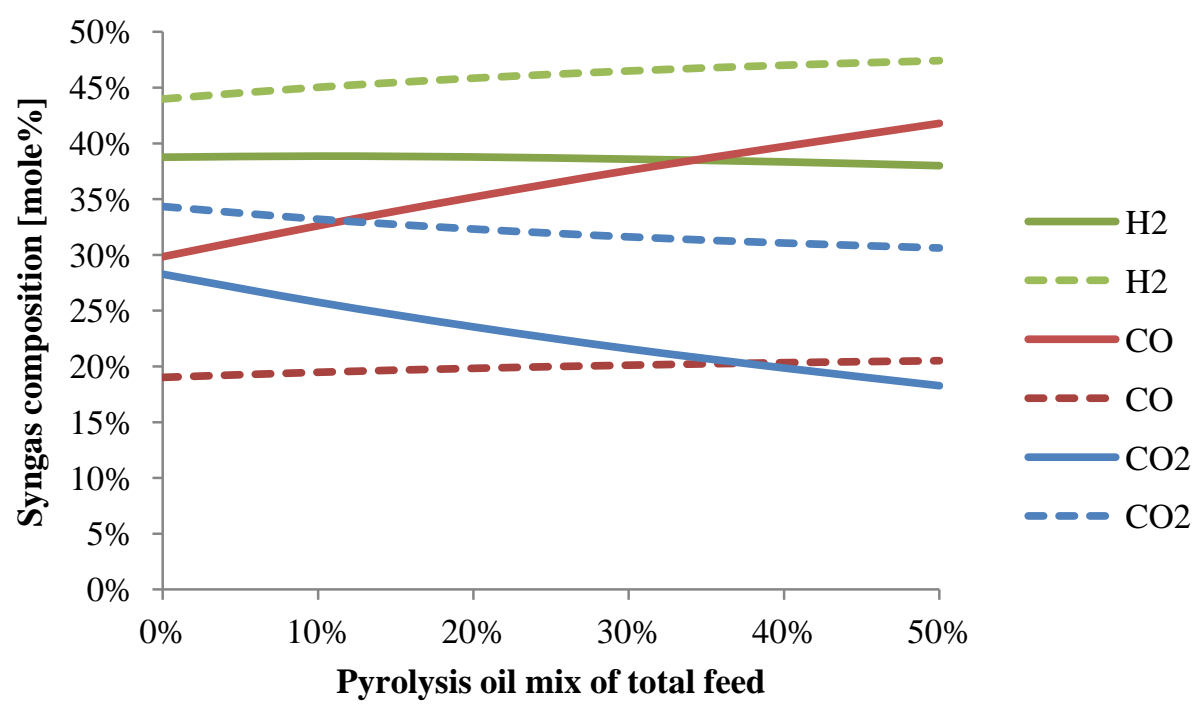

Figure 3. Composition for the major syngas components after syngas cooling (solid lines) and after the WGS (dashed lines).

The co-gasification routes seem to be advantageous with respect to energy efficiency compared to an unblended black liquor gasification route. The incremental methanol production capacity for Case 25 and Case 50 receives an overall system efficiency of $71 \%$ (calculated as electrical equivalents) which is 4\%-units higher than for Case BLG. This is because, as seen in Figure 4, gasifying a 25/75 blend (Case 25) would almost double the methanol production and a fifty-fifty blend (Case 50) increases the methanol production capacity more than $250 \%$ compared to Case BLG. For increasing blend ratios the total amount of high pressure steam generated in the boiler is reduced. A larger share of the LP steam demand of the mill is delivered from the BFP. Thereby the import of external biomass can be reduced. Although, a decreased production of HP (high pressure) steam and in combination with an increased extraction of MP from the turbine to satisfy the BFP:s steam demand, decreases the power production. However, the required power import is, calculated per ton of methanol, declining for increasing pyrolysis oil to black liquor blend ratios. Furthermore, the lime kiln fuel demand is also reduced in the co-gasification cases. Accounting the methanol production volumes in Case 25 and Case 50, the average system efficiencies are 1\%-unit and 2\%-units higher compared to the Case BLG (see Figure 5). The energy balances for all cases include required operational changes in the pulp mill due to the integration of the gasification plant. However, if also the losses during pyrolysis of the biomass to bio-oil are accounted for in the overall system efficiencies, Case BLG will receive the highest overall system efficiency (Figure 5).

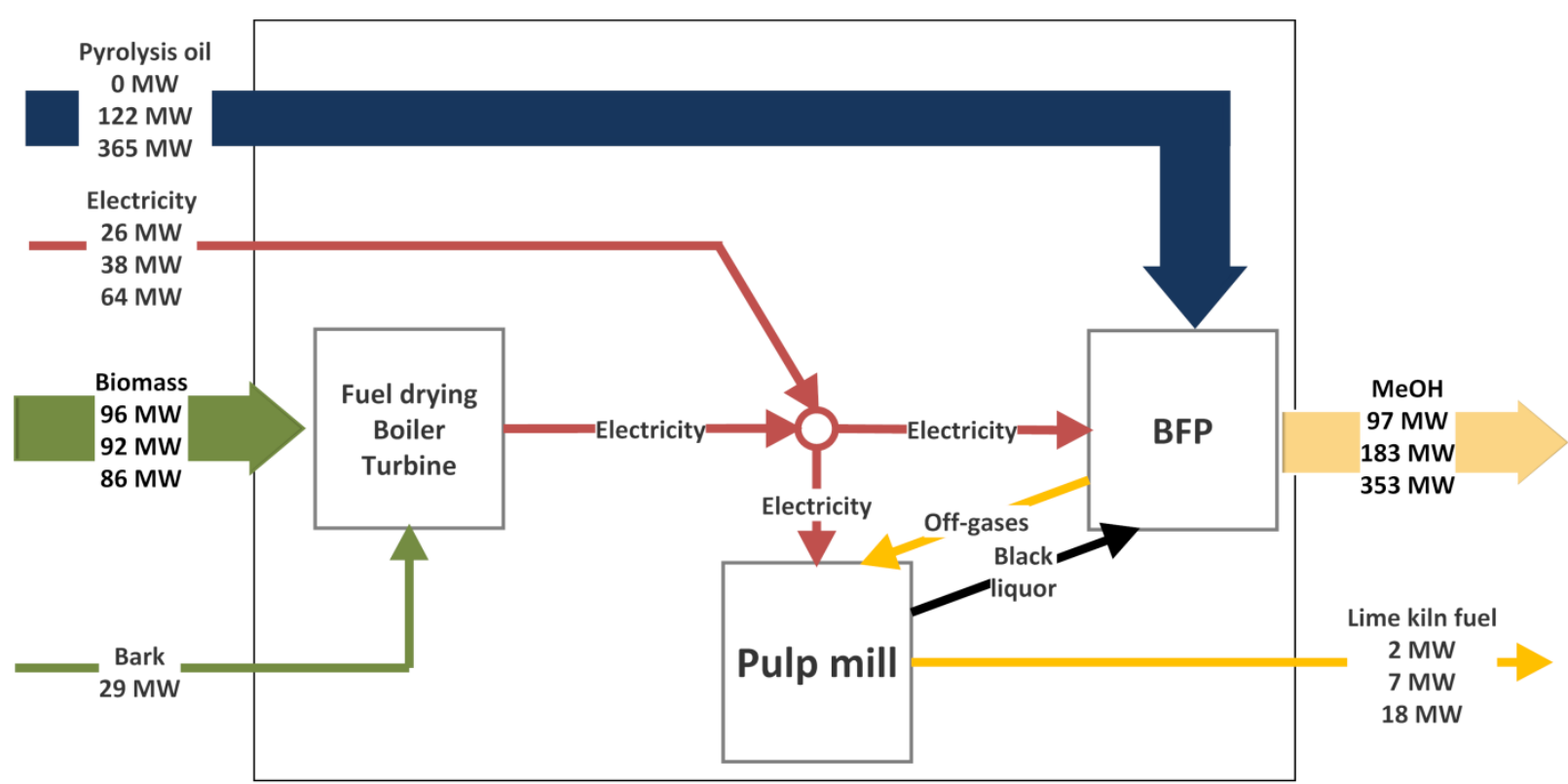

Figure 4. Incremental operating data during yearly average production compared to the rebuild recovery boiler including the utility requirements of the ASU. 


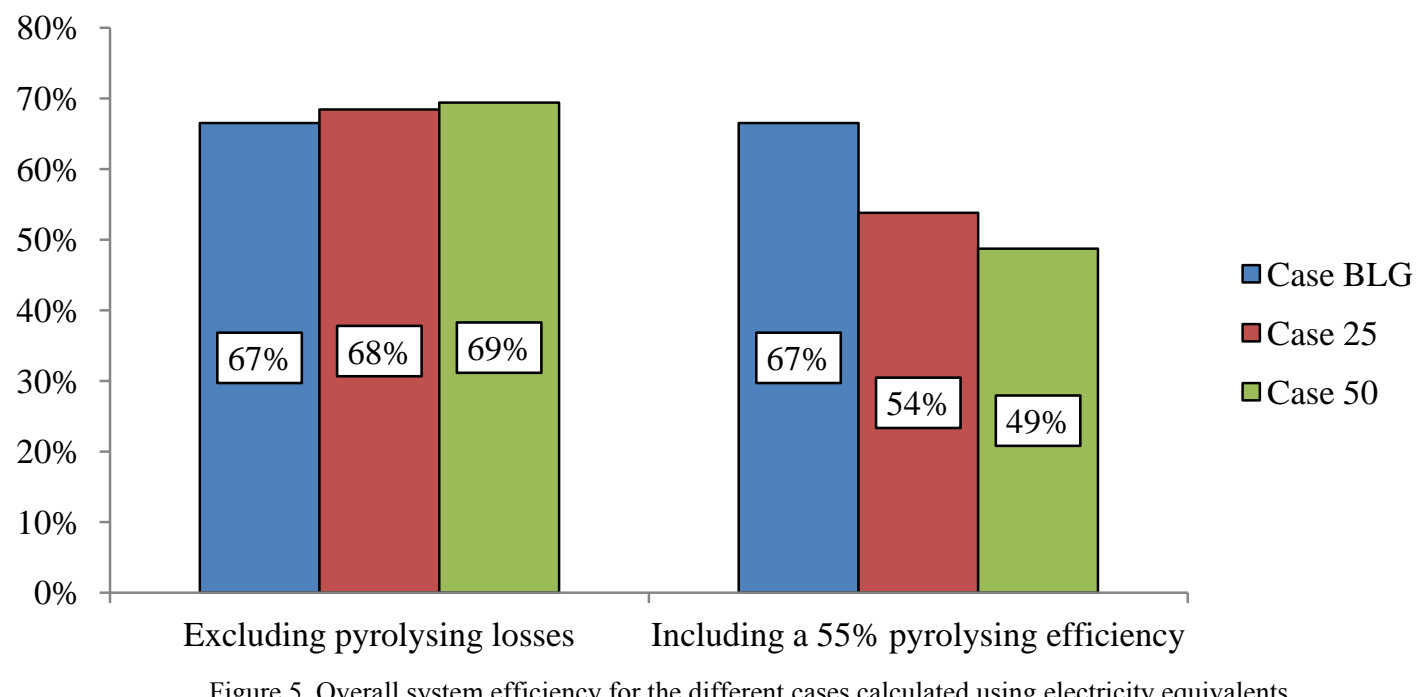

The total investment cost together with the production is presented in Table 7. Only aggregated investment cost is shown due to commercial confidentiality. For Case 25, the investment cost for the incremental production capacity is $0.83 \mathrm{M} / \mathrm{MW}_{\mathrm{MeOH}}$ corresponding value for Case 50 is surprisingly higher, $1.15 \mathrm{M} / \mathrm{MW}_{\mathrm{MeOH}}$. This indicates that increasing the methanol production capacity with $255 \mathrm{MW}$ (Case 50) would be more capital cost intensive than for Case 25. The reason is that Case 25 requires the same amount of gasifiers operating in parallel (four) as Case BLG, while Case 50 requires three more. Hence, the reduced redundancy requirement in the gasification unit contributes stronger to a reduced investment for Case 25 than Case 50 . The specific investment cost of all other units decrease with methanol production as described above.

Reasonable average pyrolysis oil price is assessed to be around $70 € / \mathrm{MWh}$ including a cost for transportation ${ }^{3}$ and a $20 \%$ profit margin. This is based on the reported production costs for different production alternatives for pyrolysis oil (integrated and standalone) and different types and qualities of biomass feedstocks used for the production. As shown in Table 7, a pyrolysis oil price of $70 € / \mathrm{MWh}$ seems to make the co-gasification pathways an attractive investment opportunity. The incremental 85 MW of methanol produced in Case 25 annually adds 53\% higher revenue (see Table 7) to the production level in Case BLG, while the investment cost is only increased by $23 \%$. Case 50 also adds extra revenue compared to the BLG production level, but the ratio between the added revenues and increased investment is slightly lower than in Case 25.

Table 7. Investment and production costs (M€ per year). A negative sign represent revenue. Case 25 and 50 are for the incremental methanol production capacity compared with Case BLG as reference.

\begin{tabular}{|c|c|c|c|}
\hline Production cost & Case BLG & Case 25 & Case 50 \\
\hline Biomass & 20.65 & -0.71 & -2.13 \\
\hline Pyrolysis oil & 0 & +63.02 & +189.05 \\
\hline Power BFP & 3.91 & +3.15 & +9.45 \\
\hline Reduced power production & 2.64 & +0.39 & +1.16 \\
\hline Oxygen BFP & 11.91 & +4.99 & +14.96 \\
\hline Bark export loss & 4.14 & 0 & 0 \\
\hline LPG to BFP & 0.11 & +0.06 & +0.15 \\
\hline Workers ${ }^{\mathrm{A}}$ and Maintenance ${ }^{\mathrm{B}}$ & 12.86 & +2.39 & +8.52 \\
\hline Reduced lime kiln fuel & -0.59 & -1.93 & -5.63 \\
\hline Other ${ }^{\mathrm{C}}$ & -5.28 & 0 & 0 \\
\hline Methanol & -130.18 & -113.76 & -341.29 \\
\hline EBITDA $^{\mathrm{D}}$ & -79.84 & -42.43 & -125.78 \\
\hline Incremental investment costs [18] & 345.31 & +80.40 & +294.13 \\
\hline
\end{tabular}

A. $80 / 85 / 90$ Employees with an average cost of $0.057 \mathrm{M} € / \mathrm{y}$.

B. $3 \%$ of the BFP investment cost assumes to include both staff and material cost and the cost for the gasifier's ceramic lining and WGS/MSY/DSY catalyst[18].

C. Avoided cost or revenues from oxygen to mill, make up chemical to mill, external lime and fuel oil to boilers

D. Earnings before interest, taxes, depreciation and amortization

${ }^{3}$ According to G. Benjaminsson, et al. Decentraliserad produktion av pyrolysolja för transport till storskaliga kraftvärmeverk och förgasningsanläggningar. In Swedish., Gasefuels AB, 2013. the transportation cost for pyrolysis oil is $2.3 € / \mathrm{MWh}$ within a 100 $\mathrm{km}$ radius with trucks or $500 \mathrm{~km}$ radius with trains. 
The IRR of the investments in all cases is presented in Figure 6. The IRR calculations are based on an equivalent comparison against the mill with the upgraded recovery boiler. The total investment in Case 50 (639.43 M€) receives the highest IRR and seems to be the better investment opportunity when the cost for pyrolysis oil is below $80 € / \mathrm{MWh}$. The added-values from cogasification in Case 50 start to diminish when the cost for pyrolysis oil exceed $90 € / \mathrm{MWh}$ (Figure 6) compared to Case BLG. Case 25 is less sensitive to the pyrolysis oil cost and would return a better IRR than Case BLG for a bio-oil cost up to $95 € /$ MWh. In fact, with Case BLG as reference, the incremental $85 \mathrm{MW}$ of methanol produced in Case 25 consistently receives a higher IRR independent on the cost of pyrolysis oil compared to the incremental methanol volumes in Case 50. This is because the reference production level consistently receives an IRR of $17.5 \%$ and the contribution of the received IRR for incremental production in Case 50 contributes more to the average IRR (Figure 6) than Case 25. Furthermore, it can be noted that the investment cost for the gasification unit is expected to decrease as experience is gathered. The co-gasification technology is new and the investment cost estimate used in this study is a first plant estimate.

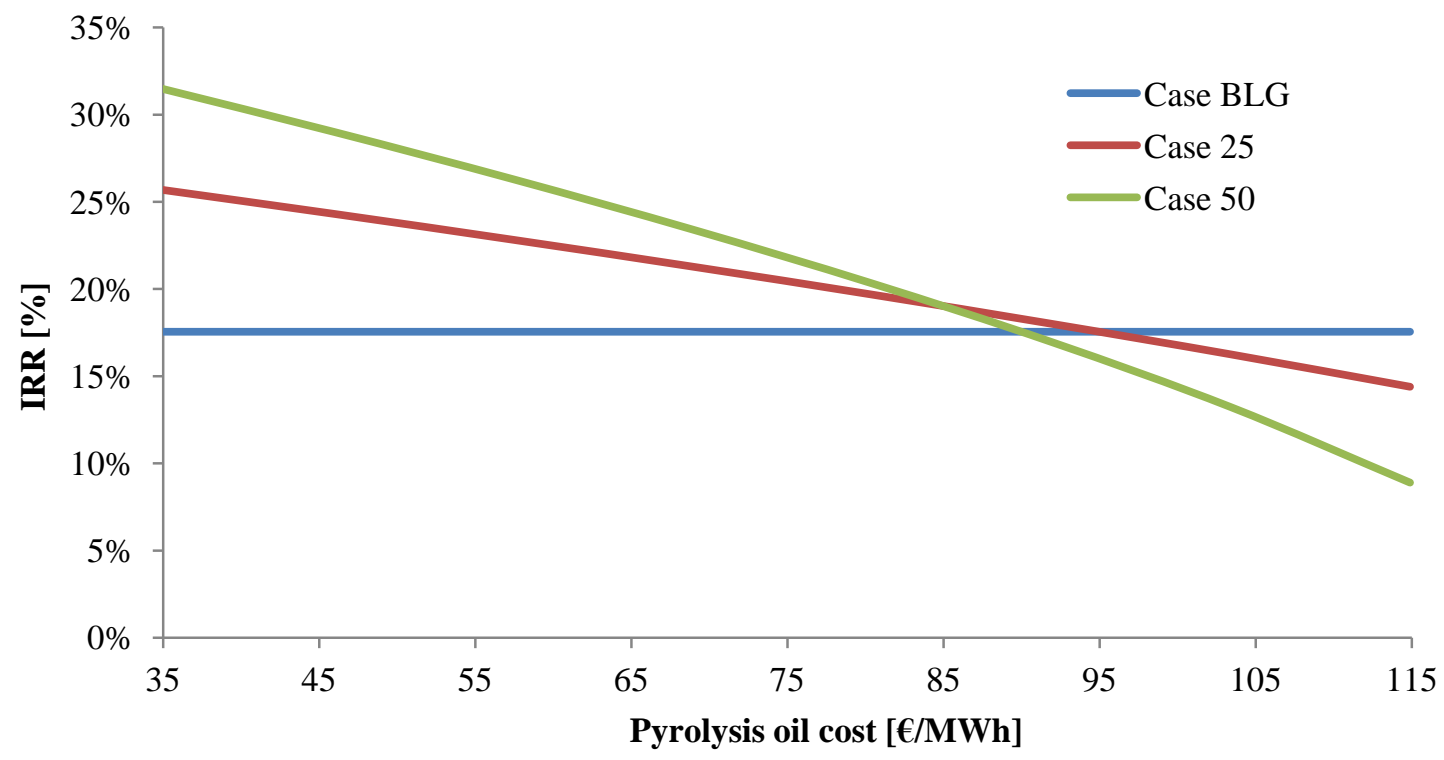

Figure 6. IRR for the incremental investment compared to upgrade recovery boiler, MeOH selling price $984 € /$ ton and no taxes considered.

\section{CONCLUSIONS}

Replacing the recovery boiler with a black liquor gasification (BLG) plant for methanol production show advantages regarding economic performance and energy efficiency. By adding pyrolysis oil to the black liquor feed, the production volumes of methanol is increased simultaneously as the plant economy and the plant efficiency are improved. Gasifying a blend consisting of $25 \%$ pyrolysis oil and $75 \%$ black liquor on a wet mass basis almost doubles the methanol production volumes, compared to only gasifying the available black liquor. A $50 / 50$ blend increases the methanol production by more than $250 \%$. The incremental methanol volumes produced from the added pyrolysis oil receives a $4 \%$-units higher overall system efficiency (calculated as electrical equivalents) than the methanol produced from the available black liquor (67\%). Although, the BLG case will receive the highest overall system efficiency if the thermal losses from the pyrolysis oil production are accounted for in the efficiency calculations.

Given that the pyrolysis oil can be produced or bought for less than roughly $90 € / \mathrm{MWh}$, increasing the methanol production via cogasification of pyrolysis oil is an attractive investment opportunity. This will add extra revenues per produced unit of methanol in comparison to methanol produced via gasification of unblended black liquor.

\section{ACKNOWLEDGMENTS}

The authors gratefully acknowledge support and collaboration of Rottneros AB and the research partner network of Bio4Energy as well as the Swedish Energy Agency for funding of this work. 


\section{REFERENCES}

[1] W. Soetaert, E. J. E. Vandamme. Biofuels. Wiley Series in Renewable Resources.Wiley., 2009.

[2] J. Andersson, J. Lundgren, C. Hulteberg, L. Malek, E. Wetterlund, K. Pettersson. System studies on biofuel production via integrated biomass gasification. Report No 2013:12, f3 The Swedish Knowledge Centre for Renewable Transportation Fuels and Foundation, Sweden. Available at www.f3centre.se, 2013.

[3] P. Carlsson, H. Wiinikka, M. Marklund, C. Gronberg, E. Pettersson, M. Lidman, et al. Experimental investigation of an industrial scale black liquor gasifier.

Part 1. The effect of reactor operation parameters on product gas composition. Fuel 89 (2010) 4025-4034.

[4] H. Wiinikka, P. Carlsson, M. Marklund, C. Gronberg, E. Pettersson, M. Lidman, et al. Experimental investigation of an industrial scale black liquor gasifier. Part 2: Influence of quench operation on product gas composition. Fuel 93 (2012) 117-129.

[5] G. van Rossum, S. R. A. Kersten, W. P. M. van Swaaij. Staged Catalytic Gasification/Steam Reforming of Pyrolysis Oil. Ind Eng Chem Res 48 (2009) 58575866 .

[6] G. van Rossum, S. R. A. Kersten, W. P. M. van Swaaij. Catalytic and Noncatalytic Gasification of Pyrolysis Oil. Ind Eng Chem Res 46 (2007) 3959-3967.

[7] D. Lindberg. Thermochemistry and melting properties of alkali salt mixtures in black liquor conversion processes. Åbo: Åbo Akademi University; 2007.

[8] O. Knacke, O. Kubaschewski, K. Hesselman. Thermochemical properties of inorganic substances. 2 ed. Stahleisen, Springer, 1991.

[9] P. Carlsson, H. Wiinikka, M. Marklund, C. Gronberg, E. Pettersson, M. Lidman, et al. Experimental investigation of an industrial scale black liquor gasifier. 1. The effect of reactor operation parameters on product gas composition. Fuel 89 (2010) 4025-4034.

[10] O. Ohrman, C. Haggstrom, H. Wiinikka, J. Hedlund, R. Gebart. Analysis of trace components in synthesis gas generated by black liquor gasification. Fuel 102 (2012) 173-179.

[11] P. Carlsson, M. Marklund, E. Furusjo, H. Wiinikka, R. Gebart. Experiments and mathematical models of black liquor gasification - influence of minor gas components on temperature, gas composition, and fixed carbon conversion. Tappi Journal 9 (2010) 15-24.

[12] Y. Q. Huang, X. L. Yin, C. Z. Wu, C. W. Wang, J. J. Xie, Z. Q. Zhou, et al. Effects of metal catalysts on CO2 gasification reactivity of biomass char. Biotechnology Advances 27 (2009) 568-572.

[13] K. Umeki, A. Moilanen, A. Gomez-Barea, J. Konttinen. A model of biomass char gasification describing the change in catalytic activity of ash. Chemical Engineering Journal 207 (2012) 616-624.

[14] M. Kajita, T. Kimura, K. Norinaga, C. Z. Li, J. Hayashi. Catalytic and Noncatalytic Mechanisms in Steam Gasification of Char from the Pyrolysis of Biomass. Energy \& Fuels 24 (2010) 108-116.

[15] E. Furusjö, R. Stare, S. Häggström. Gasification of thick liquor from a sulfite cellulose mill using pressurized high temperature entrained flow gasification International Chemical Recovery Conference. Williamsburg, Virginia, Tappi, 2010.

[16] C. L. Verrill, K. Whitty, R. Backman, M. Hupa. Pressurized gasification of black liquor - Effect of char sodium content. Journal of Pulp and Paper Science 24 (1998) 103-110.

[17] M. Karlsson. The MIND method: A decision support for optimization of industrial energy systems - Principles and case studies. Applied Energy 88 (2011) 577-589.

[18] Chemrec AB. Based on in-house knowledge of Chemrec AB., 2013.

[19] T. Ekbom, M. Lindblom, N. Berglin, P. Ahlvik. Technical and Commercial Feasibility Study of Black Liquor Gasification with Methanol/DME Production as Motor Fuels for Automotive Uses - BLGMF. ALTENER Programme Report, Contract No. 4.1030/Z/01-087/2001, 2003.

[20] P. Tunå, C. Hulteberg, J. Hansson, A. Åsblad, E. Andersson. Synergies from combined pulp\&paper and fuel production. Biomass and Bioenergy 40 (2012) 174-180.

[21] M. Mark, M. M. Wright, J. A. Satrio, C. Brown, D. E. Daugaard, D. D. Hsu. Techno-Economic Analysis of Biomass Fast Pyrolysis to Transportation Fuels. NREL/TP-6A20-46586. Golden, Colorado, USA, National Renewable Energy Laboratory (NREL), 2012.

[22] E. Sipilä. Bioenergy carriers production opportunities in Finland (Presentation). VTT torrefaction seminar, Hanasaari Cultural Center http://www.vtt.fi/files/projects/biohiili/esa_sipila.pdf. Accessed on March, 17, 2013.

[23] G. Benjaminsson, J. Benjaminsson, N. Bengtsson. Decentraliserad produktion av pyrolysolja för transport till storskaliga kraftvärmeverk och förgasningsanläggningar. In Swedish., Gasefuels AB, 2013. 